\title{
Molecular characterization and endosymbiotic localization of the gene encoding D-ribulose 1,5-bisphosphate carboxylase-oxygenase (RuBisCO) form II in the deep-sea vestimentiferan trophosome
}

\author{
Hosam Elsaied, Hiroyuki Kimura and Takeshi Naganuma
}

Author for correspondence: Takeshi Naganuma. Tel: +81 82424 7986. Fax: + 81824227059.
e-mail: takn@hiroshima-u.ac.jp

School of Biosphere Sciences, Hiroshima University, 1-4-4 Kagamiyama, HigashiHiroshima, 739-8528, Japan
To better understand the contribution of micro-organisms to the primary production in the deep-sea gutless tubeworm Lamellibrachia sp., the 16S-rDNAbased phylogenetic data would be complemented by knowledge of the genes that encode the enzymes relevant to chemoautotrophic carbon fixation, such as D-ribulose 1,5-bisphosphate carboxylase-oxygenase (RuBisCO; EC 4.1.1.39). To phylogenetically characterize the autotrophic endosymbiosis within the trophosome of the tubeworm Lamellibrachia sp., bulk trophosomal DNA was extracted and analysed based on the 16S-rRNA- and RuBisCO-encoding genes. The 16S-rRNA- and RuBisCO-encoding genes were amplified by PCR, cloned and sequenced. For the $16 \mathrm{~S}$ rDNA, a total of 50 clones were randomly selected and analysed directly by sequencing. Only one operational taxonomic unit resulted from the 165 rDNA sequence analysis. This may indicate the occurrence of one endosymbiotic bacterial species within the trophosome of the Lamellibrachia sp. used in this study. Phylogenetic analysis of the 165 rDNA showed that the Lamellibrachia sp. endosymbiont was closely related to the genus Rhodobacter, a member of the $\alpha$-Proteobacteria. For the RuBisCO genes, only the form II gene (cbbM) was amplified by PCR. A total of $50 \mathrm{cbbM}$ clones were sequenced, and these were grouped into two operational RuBisCO units (ORUs) based on their deduced amino acid sequences. The cbbM ORUs showed high amino acid identities with those recorded from the ambient sediment bacteria. To confirm the results of sequence analysis, the localization of the symbiontspecific 165 rRNA and cbbM sequences in the Lamellibrachia sp. trophosome was visualized by in situ hybridization (ISH), using specific probes. Two types of cells, coccoid and filamentous, were observed at the peripheries of the trophosome lobules. Both the symbiont-specific 165 rDNA and cbbM probes hybridized at the same sites coincident with the location of the coccoid cells, whereas the filamentous cells showed no cbbM-specific signals. The RuBisCO form I gene (cbbL) was neither amplified by PCR nor detected by ISH. This is the first demonstration of chemoautotrophic symbiosis in the deep-sea gutless tubeworm, based on sequence data and in situ localization of both the 165rRNA- and RuBisCO-encoding genes.

Keywords: Lamellibrachia endosymbiont, $16 \mathrm{~S}$ rDNA, cbbM, phylogenetic analysis, in situ hybridization

Abbreviations: ISH, in situ hybridization; NJ, neighbour-joining; ORU, operational RuBisCO unit; OTU, operational taxonomic unit; RuBisCO, D-ribulose 1,5bisphosphate carboxylase-oxygenase.

The DDBJ accession numbers for the sequences reported in this paper are AB042416 [ST-Sym(16S)-1], AB032829 [ST-Sym(II)-1] and AB040509 [ST-Sym(II)-2]. 


\section{INTRODUCTION}

The concept of the sustainment of animal life by bacterial chemoautotrophy has been reviewed for the vestimentiferan tubeworms inhabiting hydrothermal vents and cold seeps (Felbeck, 1981; Cavanaugh, 1983; Julian et al., 1999). Three lines of evidence currently support this concept. The first piece of evidence for chemoautotrophic symbiosis is based on microscopic observations that demonstrated the intracellular occurrence of prokaryotic cells in the specialized organ of vent tubeworms, the trophosome. The vent tubeworm Riftia pachyptila harbours $3 \times 10^{9}$ prokaryotic cells per gram of trophosome (Cavanaugh et al., 1981). The trophosome mass often accounts for $40-60 \%$ of the total body mass of the worm, making the worm a 'chemoautotrophic animal' (Felbeck \& Childress, 1988).

The trophosome of the vestimentiferan tubeworms consists of lobules (Hand, 1987). Prokaryotic cells are localized in specialized cells - the bacteriocytes - located at the peripheries of these lobules (Cary et al., 1993). Morphologically diverse micro-organisms have been observed in the trophosomal tissue of the seep tubeworm Lamellibrachia sp. (Naganuma et al., 1997a). In the vent tubeworm Riftia pachyptila, the trophosome consists of distinct zones that harbour morphologically distinct prokaryotes: rod-like prokaryotes are found in the inner zone of the lobules and coccoid prokaryotes are found in the outer zone of the lobules (Bright et al., 2000).

The second piece of evidence for chemoautotrophic symbiosis within the trophosome of vestimentiferan tubeworms is the detection and amplification of bacterial rRNA and rDNA from the contents of the trophosome (Stahl et al., 1984; Distel et al., 1994; Di Meo et al., 2000). Intracellular localization of thiobacillic $16 \mathrm{~S}$ rRNA sequences in the trophosome of the vent tubeworm Riftia pachyptila was demonstrated by in situ hybridization (ISH; Cary et al., 1993), whereas the $16 \mathrm{~S}$ rRNA of a member of the $\varepsilon$-Proteobacteria was detected and localized in the trophosome of the seep tubeworm Lamellibrachia sp. (Naganuma et al., 1997b).

The third piece of evidence for chemoautotrophic symbiosis in tubeworms was the detection of enzymes that catalyse the fixation of radioactive bicarbonate via the Calvin-Benson cycle (Felbeck et al., 1981). The enzyme that mediates the first step of carbon fixation is D-ribulose 1,5-bisphosphate carboxylase-oxygenase (RuBisCO; EC 4.1.1.39), which serves as an indicator for autotrophy. RuBisCO is localized in intracellular polyhedral bodies (carboxysomes) in the endosymbiont of the vent tubeworm Ridgeia spp. (De Burgh et al., 1989). The enzyme has three forms, namely form I, form II and archaeal RuBisCO, which are distinct from each other on the basis of their structures, and their physical and chemical properties (Kellogg \& Juliano, 1997; Watson et al., 1999). The RuBisCO form I largesubunit gene $(c b b L)$ was sequenced from the endosymbionts of the vent gastropod Alvinoconcha hessleri and the mussel Bathymodiolus sp. (Stein et al., 1990; Elsaied
\& Naganuma, 2001), whereas the RuBisCO form II gene ( $c b b M)$ was sequenced from the endosymbionts of the vent tubeworm Riftia pachyptila (Robinson et al., 1998) and the cold-seep tubeworm Lamellibrachia sp. (Elsaied \& Naganuma, 2001).

In this study, we describe the use of both $16 \mathrm{~S}$ rDNA and RuBisCO sequences to phylogenetically characterize only the autotrophic endosymbiotic bacteria from the natural microbial community within the trophosome of the tubeworm Lamellibrachia sp. We also demonstrate the localization of both the endosymbiotic 16S rRNA and $\mathrm{RuBisCO}$ form II $c b b M$ sequences within the trophosome by using ISH with specific oligo- and polynucleotide probes, respectively.

\section{METHODS}

Tubeworm collection and pre-treatment of the symbiontcontaining trophosome. Individuals of Lamellibrachia sp. were collected from a bathyal methane-rich seep $[1199 \mathrm{~m}$ deep, Sagami Trough $\left(35^{\circ} 00 \cdot 2^{\prime} \mathrm{N}, 139^{\circ} 20 \cdot 5^{\prime} \mathrm{E}\right)$, Japan] during the 1142 nd dive of the manned-submersible Shinkai 2000 (Japan Marine Science and Technology Centre). Immediately after retrieval, the soft body tissue of the samples was pulled out of the external chitinous tube and rinsed gently in filter-sterilized $(0 \cdot 2 \mu \mathrm{m}$ filter $)$ autoclaved seawater. Part of the soft body tissue of the specimens was fixed onto a board with $4 \%$ paraformaldehyde in PBS $(137 \mathrm{mM} \mathrm{NaCl} ; 2.7 \mathrm{mM}$ $\left.\mathrm{KCl} ; 10.6 \mathrm{mM} \mathrm{Na} \mathrm{HPO}_{4} ; 1.5 \mathrm{mM} \mathrm{KH}_{2} \mathrm{PO}_{4} ; \mathrm{pH} 7.5\right)$, in preparation for ISH. The other part of the soft body tissue was used for DNA analysis. To remove any contaminating extracellular bacteria and free DNA from the trophosome tissue before DNA extraction, the tissue was treated according to the method of Elsaied \& Naganuma (2001). The trophosomal tissue was suspended in TE buffer $(10 \mathrm{mM}$ Tris; $1 \mathrm{mM}$ EDTA; $\mathrm{pH} 8)$ and incubated with lysozyme $\left(1 \mathrm{mg} \mathrm{ml}^{-1}\right)$ at room temperature for $30 \mathrm{~min}$. The tissue was then treated with DNase $\left(10 \mu \mathrm{g} \mathrm{ml}^{-1}\right)$ and $\mathrm{MgCl}_{2}\left(0.02 \mathrm{mM} \mathrm{ml}^{-1}\right)$ at $37^{\circ} \mathrm{C}$ for $5 \mathrm{~min}$, and washed several times with TE buffer with a higher concentration of EDTA (50 mM Tris; $50 \mathrm{mM}$ EDTA; pH 8) to remove any residual $\mathrm{DNa}$ ase and $\mathrm{MgCl}_{2}$. The cleaned tissue was kept at $-80^{\circ} \mathrm{C}$ for DNA analysis.

Genomic DNA extraction, PCR, cloning and sequencing of the 16S-rRNA- and RuBisCO-encoding genes. The extraction of trophosomal DNA, amplification of the genes of interest by PCR, and the cloning and sequencing of these genes was performed according to the methods of Distel et al. (1994) and Elsaied \& Naganuma (2001). The primers used in the amplification of the $16 \mathrm{~S}$ rDNA were $27 \mathrm{~F}$ and $1492 \mathrm{R}$, specific for the amplification of eubacterial 16S rDNA (DeLong, 1992). The expected amplified product was equivalent to approximately 1484 bp of Escherichia coli $16 \mathrm{~S}$ rDNA. Approximately $400 \mathrm{bp}$ of $c b b M$ were amplified from the bulk trophosomal DNA using specific primers and PCR conditions, as detailed in Elsaied \& Naganuma (2001). Fifty clones containing the target inserts were selected randomly from both the $16 \mathrm{~S}$ rDNA and $c b b M$ clone libraries, and these were sequenced. The obtained sequences (1427 bp for the $16 \mathrm{~S}$ rDNA and $400 \mathrm{bp}$ for $c b b M$ ) were screened against sequences contained within the databases held at the DNA Database of Japan (DDBJ) (http:// www.ddbj.nig.ac.jp) using the program FASTA 3. For the $16 \mathrm{~S}$ rDNA, the sequences showing $97 \%$ nucleotide identity with each other were grouped into one operational taxonomic unit (OTU) (Godon et al., 1997). The resulting nucleotide se- 
quences of $c b b M$ were translated into amino acids using the program PROTEIN ENGINE (available at the EBI website; http://www.ebi.ac.uk). The current $c b b M$ sequences sharing $100 \%$ amino acid identity with each other were grouped into an operational RuBisCO unit (ORU). One OTU resulted from the nucleotide sequence analysis of the $5016 \mathrm{~S}$ rDNA clones, and this was named ST-Sym(16S)-1. Two ORUs resulted from the amino acid sequence analysis of $c b b M$, and these were grouped into ST-Sym(II)-1 and ST-Sym(II)-2, representing 38 and 12 clones, respectively, of the $50 \mathrm{cbbM}$ clones that were analysed. Each OTU or ORU was represented by the clone that displayed the highest similarity (with respect to nucleotide sequence) with the other clones within the same OTU or ORU. Two phylogenetic trees were constructed based on multiple alignments of the nucleotide and deduced amino acid sequences for the $16 \mathrm{~S}$ rDNA OTU and the cbbM ORUs, respectively, and these included other sequences from the databases. The phylogenetic trees were constructed using the neighbour-joining (NJ) method (Saitou \& Nei, 1987), and were visualized using the program TREEviEw (Page, 1996). The branching patterns of the constructed phylogenetic trees were confirmed by reconstruction of the phylogenies using two other methods of analysis, namely maximum-parsimony and maximum-likelihood, contained within the PHYLIP package (Felsenstein, 1989).

The ST-Sym(16S)-1, ST-Sym(II)-1 and ST-Sym(II)-2 sequences obtained in this study were deposited in the DDBJ under accession numbers AB042416, AB032829 and AB040509, respectively.

Preparation of the oligonucleotide 16S rDNA probes. The oligonucleotide 16S-rRNA-targeted probe specific for the autotrophic Lamellibrachia sp. endosymbiont was designed from the sequence ST-Sym(16S)-1, by creating a multiple alignment with this sequence and those sequences retrieved from the database. The alignment was created with the program CLUSTAL $\mathrm{w}$ (Thompson et al., 1989). The endosymbiont-specific $16 \mathrm{~S}$-rRNA-targeted probe Lam-384R (5'GCCTGCGCCCATTGTCTAAGATCCC-3') was complementary to nucleotide positions 360-384 of E. coli $16 \mathrm{~S}$ rDNA. The mismatching of the probe target region with $16 \mathrm{~S}$ rDNA sequences from other species was checked by homology searches of the sequences contained within the databases (DDBJ, EMBL, GenBank and RDP) using the programs BLAST and РRове матсн (Altschul et al., 1990; Olsen et al., 1991).

The universal eubacterial 16S-rRNA-targeted probe EUB338 (5'-GCTGCCTCCCGTAGGAGT-3'), complementary to nucleotide positions 338-355 of E. coli 16S rDNA (Amann et al., 1990), was used as a positive control, to localize all possible bacterial species within the trophosome. The oligonucleotide probes were chemically synthesized by Roche and were labelled using the Digoxigenin 3 '-end Labelling Kit (Boehringer Mannheim), according to the manufacturer's instructions.

Preparation of the RuBisCO form II $\boldsymbol{c b b M}$ probe. To obtain a $c b b M$ probe, characterized by its efficiency to produce a $c b b M$-specific ISH signal in trophosome tissue, probes with different lengths (short oligonucleotides, typically $<50$-mer single-stranded DNA fragments, and long, $400 \mathrm{bp}$ DNA fragments) were designed from the sequence alignments created for ST-Sym(II)-1 and ST-Sym(II)-2 (data not shown). The short probes were prepared and labelled in the same way as the $16 \mathrm{~S}$ rDNA probes. The $400 \mathrm{bp}$ fragment, representing the full-length ST-Sym(II)-2 sequence, was chosen as the $c b b M$ probe, as the nucleotide sequence divergence within the
ST-Sym(II)-2 ORU was as low as $1 \%$. This was contrasted by the higher nucleotide sequence divergence $(8 \cdot 8 \%)$ seen within the ST-Sym(II)-1 ORU, which would have resulted in a degenerative probe that would have given a less specific ISH signal. The $c b b M$ ST-Sym(II)-2 fragment was amplified by PCR from the plasmid of a transformed TOP10 E. coli clone. The fragment was purified by using the Qiagen QIAquick PCR Purification Kit (Germany) and labelled by randompriming with digoxigenin-11-dUTP, using the DIG-High Prime Kit (Boehringer Mannheim) according to the manufacturer's instructions.

The specificities of the $16 \mathrm{~S}$ rDNA and the RuBisCO $c b b M$ probes for their target sequences were checked by Southern dot-blot hybridization using a positive high-bond nylon membrane (Amersham Pharmacia Biotech), according to the method of Cary et al. (1993). The efficiency of these probes to produce ISH signals was also evaluated, using sections of the trophosomal tissue.

Detection of the RuBisCO form I cbbL gene by PCR and ISH. The primers and PCR conditions used to test the amplification of the $c b b L$-encoding gene from bulk trophosomal DNA were as described in Elsaied \& Naganuma (2001). cbbL was not amplified from the Lamellibrachia sp. trophosomal DNA. To confirm the absence of this gene in the Lamellibrachia sp. trophosome, ISH was performed using a $c b b L$-specific probe. Approximately 800 bp were amplified by PCR from the $c b b L$ gene of the endosymbiont of the deep-sea mussel Bathymodiolus sp. (Elsaied \& Naganuma, 2001). The $800 \mathrm{bp} c b b L$ probe, named Bathy $(c b b L)-1$, was labelled by random-priming with digoxigenin-11-dUTP, using the DIG-High Prime Kit. The efficiency of Bathy $(c b b L)-1$ to produce a $c b b L$-specific ISH signal was tested on a section of gill tissue from Bathymodiolus sp. The probe was also used to test for the possible presence of RuBisCO form I $c b b L$ within the trophosome of the tubeworm, Lamellibrachia sp., used in this study.

ISH procedure. To visualize the localization of the endosymbiotic 16S-rRNA and RuBisCO sequences within the tubeworm trophosome, ISH was performed on consecutive paraffin cross sections of the trophosome, using a modified method of Naganuma et al. (1997b). Before ISH, the trophosomaltissue sections were de-paraffinized in xylene and were rehydrated by immersing them in a decreasing series of ethanol $(100,95,90,80$ and $70 \%)$ for $5 \mathrm{~min}$ at each level, followed by a final wash for $5 \mathrm{~min}$ in $\mathrm{H}_{2} \mathrm{O}$. The sections were then treated with $0.2 \%$ Triton X-100 in PBS for $1.5 \mathrm{~min}$, followed by digestion with $100 \mu \mathrm{g}$ proteinase $\mathrm{K} \mathrm{ml}^{-1}$ at $37^{\circ} \mathrm{C}$ for $15 \mathrm{~min}$. The digested sections were treated with $0 \cdot 1 \%$ glycine and were post-fixed in $4 \%$ paraformaldehyde for $5 \mathrm{~min}$. They were then washed in PBS. The sections were treated with $0.25 \%(\mathrm{v} / \mathrm{v})$ acetic anhydrite in $0.1 \mathrm{M}$ triethanolamine $(\mathrm{pH} 8)$ for $10 \mathrm{~min}$, and equilibrated in $2 \times \mathrm{SSPE}$ [diluted from a $20 \times$ SSPE stock solution ( $3 \mathrm{M} \mathrm{NaCl} ; 0 \cdot 2 \mathrm{M} \mathrm{NaH}_{2} \mathrm{PO}_{4} . \mathrm{H}_{2} \mathrm{O}$; 20 mM EDTA; pH 7.4)]. Sections for ISH were dehydrated in an ascending series of ethanol (70,95 and $100 \% ; 5$ min each dehydration step) and then air-dried. Slides can be stored at room temperature until the hybridization step.

Slides were prepared for hybridization by immersing them in hybridization buffer that contained $0.5 \mathrm{mg}$ salmon-sperm DNA ml ${ }^{-1}, 0 \cdot 25 \mathrm{mg}$ yeast tRNA $\mathrm{ml}^{-1}$ and $5 \times$ Denhardt's reagent in $2 \times$ SSPE. They were then incubated for $40 \mathrm{~min}$ at $37^{\circ} \mathrm{C}$. One hundred nanograms of the digoxigenin-labelled probe was mixed with $100 \mu \mathrm{l}$ of the fresh hybridization buffer, and this mixture was added to each slide section. The slides 
were then sealed with rubber cement. The probe and target sequences were denatured by placing the slides on a heating plate at $100{ }^{\circ} \mathrm{C}$ for $10 \mathrm{~min}$. The slides were then incubated in a sealed humid chamber overnight at $43^{\circ} \mathrm{C}$ for hybridization. Thereafter, the sections were washed consecutively in $2 \times, 1 \times$ and $0 \cdot 2 \times$ SSPE for $30 \mathrm{~min}$ at room temperature, followed by a final high-stringency wash in $0.2 \times \mathrm{SSPE}$ at $45^{\circ} \mathrm{C}$ for $1 \mathrm{~h}$ to remove any unbound probe. The sections were then equilibrated in pre-blocking buffer $(100 \mathrm{mM}$ Tris; $150 \mathrm{mM}$ $\mathrm{NaCl}$; pH 7.5) for 5 min and incubated in pre-blocking buffer supplemented with $1 \%$ blocking agent (Boehringer Mannheim) for $30 \mathrm{~min}$ at room temperature. An alkaline-phosphatase-conjugated digoxigenin-specific $\operatorname{IgG}$ (anti-dig) (Boehringer Mannheim) was used to detect the hybridization signals with enhanced sensitivity. Approximately $100 \mu \mathrm{l}$ of diluted anti-dig ( $1: 400$ blocking buffer) was applied to each section under a coverslip, and these were incubated in a sealed humidified chamber overnight at room temperature. To remove any unbound anti-dig, the sections were washed twice in pre-blocking buffer for $15 \mathrm{~min}$, with shaking. They were then equilibrated in colouring buffer $(100 \mathrm{mM}$ Tris base; $100 \mathrm{mM} \mathrm{NaCl} ; 50 \mathrm{M} \mathrm{MgCl}_{2}$; $\left.\mathrm{pH} 9 \cdot 5\right)$. The sections were incubated with a colour solution containing $0.4 \mathrm{mg}$ nitrotetrazolium blue chloride $\mathrm{ml}^{-1}, 0 \cdot 19 \mathrm{mg}$ 5-bromo-4-chloro-3indolyl-phosphate $p$-toluidine salt $\mathrm{ml}^{-1}, 50 \mathrm{mM} \mathrm{MgSO}_{4}$ and $100 \mathrm{mM}$ Tris buffer (pH 9.5) in the dark until the colour developed. Once the colour had started to precipitate, the reaction was stopped by washing the sections with $1 \times \mathrm{TE}$ buffer (10 mM Tris; $1 \mathrm{mM}$ EDTA; pH 8.0). The tissue sections were then examined using a light microscope.

To visualize the lobular structure of the trophosomal tissue, non-hybridized trophosome sections were stained by the standard double-staining method, using a haematoxylin/eosin dye mixture (Dealtry \& Rickwood, 1992).

\section{RESULTS AND DISCUSSION}

\section{Occurrence of an autotrophic endosymbiotic species within the trophosome of Lamellibrachia sp., based on 16S rDNA sequence analysis}

Only one OTU was recorded from the sequence analysis of a total of $5016 \mathrm{~S}$ rDNA clones. This may indicate the existence of only one endosymbiotic species within the trophosome of the Lamellibrachia sp. studied here. The phylogenetic analyses performed using NJ, maximum-parsimony and maximum-likelihood methods (only the tree based on NJ is shown in Fig. 1) placed the Lamellibrachia sp. endosymbiont within the cluster of $\alpha$-Proteobacteria, which includes autotrophic bacteria of the genera Rhodobacter and Rhodospirillum. This is in contrast with other tubeworm endosymbionts, which commonly belong to the $\gamma$-Proteobacteria (Feldman et al., 1997; Di Meo, 2000). The bootstrap value of $87 \%$ obtained from NJ analysis demonstrates that the association of our endosymbiont with Rhodobacter sulfidophilus (Imhoff, 1989) is statistically significant, suggesting that the Lamellibrachia sp. endosymbiont is a member of the genus Rhodobacter. The occurrence of an endosymbiont belonging to the $\alpha$-Proteobacteria in the tubeworm Lamellibrachia sp. suggests that this endosymbiont may form a unique phylogenetic lineage among the endosymbionts of other tubeworms (Feldman et al., 1997).

\section{Occurrence of a single RuBisCO gene in the trophosome of the Lamellibrachia sp.}

The RuBisCO form II gene ( $c b b M)$ was amplified from the bulk trophosomal DNA, whereas the RuBisCO form I gene $(c b b L)$ was not amplified from the same bulk trophosomal DNA. The existence of $c b b M$ and the absence of $c b b L$ in the tubeworm endosymbiont could be explained in two ways. The first possible explanation is based on the observed $\delta^{13} \mathrm{C}$ value of $-11 \%$ for the vestimentiferan organic carbon assimilated by $\mathrm{RuBis} \mathrm{CO}$ form II, whereas the molluscan organic carbon assimilated by RuBisCO form I has a $\delta^{13} \mathrm{C}$ value of $-30 \%$ (Robinson \& Cavanaugh, 1995). The form II enzyme has a smaller kinetic isotope effect with respect to $\mathrm{CO}_{2}$ than does form I (Tabita, 1988). Thus, the ${ }^{13} \mathrm{C}$-enriched stable carbon isotope signature observed in the intact $-11 \%$ vestimentiferan symbioses appears to be at least partially due to this diminished enzymic discrimination (Robinson \& Cavanaugh, 1995). However, the $\delta^{13} \mathrm{C}$ value for the current vestimentiferan Lamellibrachia sp. tissue used in this study was not determined and future measurement is needed to support this explanation. The second explanation is based on the chemical and kinetic properties of $\mathrm{RuBisCO}$ form II. The RuBisCO form II enzyme potentially functions better in micro-aerobic conditions with a high $\mathrm{CO}_{2}$ concentration (Haygood, 1996). The vestimentiferan tubeworms bear endosymbionts in the trophosome, which is buried deep within the body of the animal. In this site, the low $\mathrm{O}_{2}$ and high $\mathrm{CO}_{2}$ concentrations are tightly controlled by the blood flow of the animal. The micro-aerobic condition within the trophosome allows the chance for the expression of cbbM (Stein \& Felbeck, 1993). Thus, the physiological constraints within the host animal may allow preferential selection of the $c b b M$-bearing endosymbionts.

The occurrence of $c b b M$ within the trophosome of Lamellibrachia sp. supports the results of the $16 \mathrm{~S} \mathrm{rDNA}$ analyses, which showed the presence of an $\alpha$-Proteobacteria-like endosymbiont. This is because the autotrophic $\alpha$-Proteobacteria have the ability to fix $\mathrm{CO}_{2}$ with the RuBisCO form II enzyme, using sulfide and thiosulfate as electron donors (Imhoff, 1989). These conditions are optimum within the trophosome (Nargang et al., 1984; Tabita, 1995; Haygood, 1996). Moreover, the endosymbiont of Riftia pachyptila bears $c b b M$ that is closely related to that of an autotrophic member of the $\alpha$-Proteobacteria, Rhodospirillum rubrum (Robinson et al., 1998). This implies that Proteobacteria-like cbbM may be distributed widely among the vestimentiferan tubeworms. Studies on $c b b M$ genes from other species of vestimentiferan endosymbionts are needed to support these observations.

\section{Analysis of the cbbM sequences of ORU ST-Sym(II)-1 and ST-Sym(II)-2}

To show the catalytic site amino acids within the ORUs, ST-Sym(II)-1 and ST-Sym(II)-2, their sequences were aligned with the sequences retrieved from the databases. The alignment of these partial amino acid sequences 

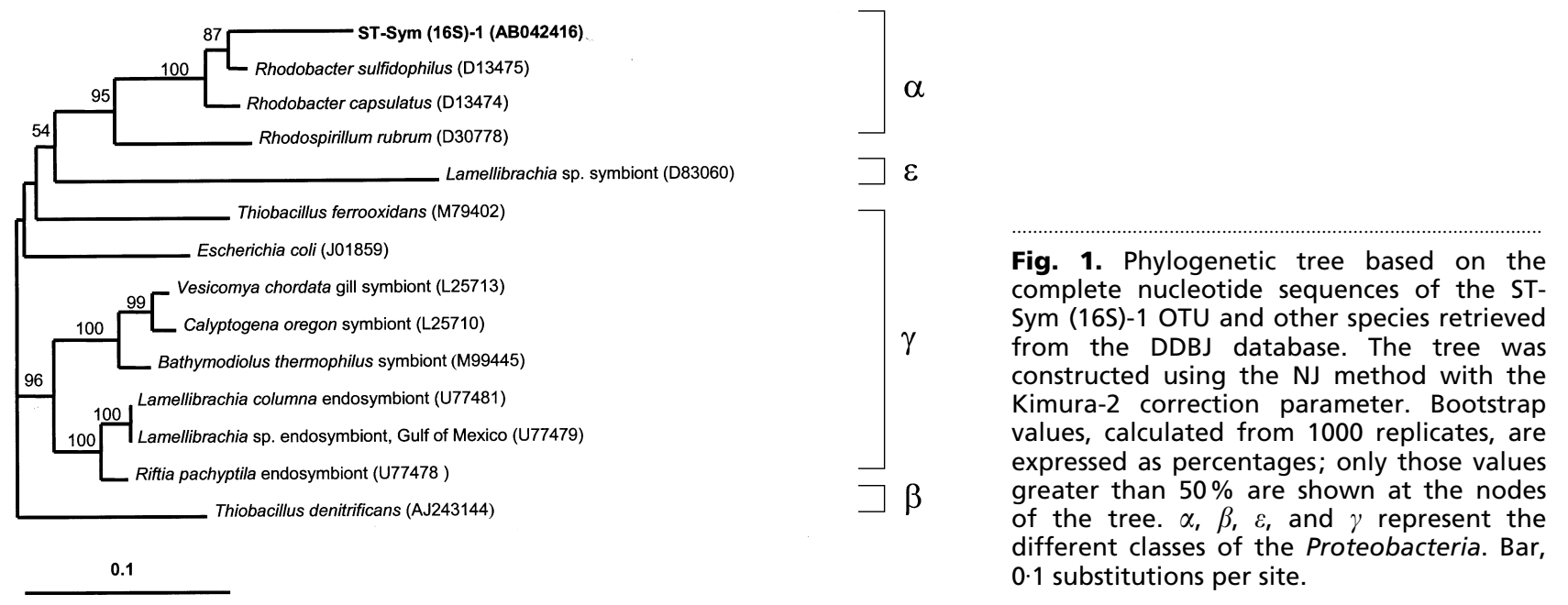

ST-Sym (II) - I
ST-Sym(II) -
ST-Sed(II)-1
ST-Sed(II)-2
Riftia pachyptila endosymbiont
Rhodospirillum rubrum
Thiobacillus denitrificans
Synechococcus sp. PCC 601
Methanococcus jannaschii

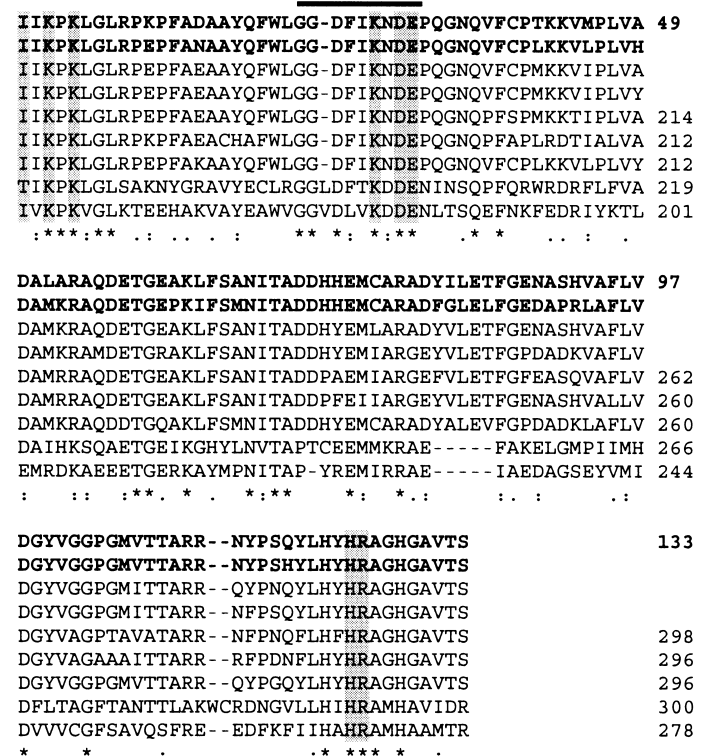

ST-SYm (II) - I

ST-Sym (II) -

ST-Sed (II) - I

ST-Sed (II) - 2

Riftia pachyptila endosymbiont

Rhodospirillum rubrum

Thiobacillus denitrificans

Synechococcus sp. PCC6301

Methanococcus jannaschii

ST-SYm (II) - I

ST-SYm (II) -

ST-Sed (II) - I

ST-Sed (I I) - 2

Riftia pachyptila endosymbiont

Rhodospirillum rubrum

Thiobacillus denitrificans

Synechococcus sp. PCC6301

Methanococcus jannaschii

\begin{abstract}
Fig. 2. Alignment of the deduced partial RuBisCO $c b b M$ amino acid sequences of ST-Sym(II)-1 and ST-Sym(II)-2 with other $c b b M$ sequences and representatives of the form I and archaeal RuBisCOs from Synechococcus sp. PCC6301 and Methanococcus jannaschii, respectively. Multiple sequence alignments were created by using CLUSTAL W. The accession numbers for the amino acid sequences that were used to create the multiple alignment are as follows: ST-Sym(II)-1, AB032829; ST-Sym(II)-2, AB040509; ST-Sed(II)-1, AB040504; ST-Sed(II)-2, AB040505; Riftia pachyptila endosymbiont, AF047688; Rhodospirillum rubrum, X00286; Thiobacillus denitrificans, L37437; Synechococcus sp. PCC6301, X03220; Methanococcus jannaschii, U67564. The amino acids that were identical in all of the aligned sequences are marked with asterisks, conserved substitutions are marked with colons, and semi-conserved substitutions are marked with periods. The shaded regions represent the known catalytic-site amino acids (Schneider et al., 1990). The characteristic RuBisCO motif sequence, GGDFIKNDE, is indicated by a thick, solid line. The numbers of the aligned cbbM amino acid positions are shown at the right side.
\end{abstract}

corresponded to amino acid positions 164-296 of the cbbM of Rhodospirillum rubrum (Schneider et al., 1990) (Fig. 2). The two cbbM ORUs shared $86 \%$ amino acid sequence identity and had the characteristic RuBisCO motif sequence (GGDFIKNDE) that has been found in other RuBisCOs (Schneider et al., 1990; Newman \& Gutteridge, 1993). The ST-Sym(II)-1 and ST-Sym(II)-2 cbbM amino acid sequences also showed conservation of the known consensus catalytic site amino acids. The conserved region is flanked by a lysine at position 191, corresponding to the sequence of Rhodospirillum rubrum. This conserved region has been identified in other RuBisCOs as the binding site for $\mathrm{CO}_{2}$, and has been shown to be involved in carbamate formation during enzyme activation (Miziorko \& Lorimer, 1983; Schneider et al., 1990). The other known active 


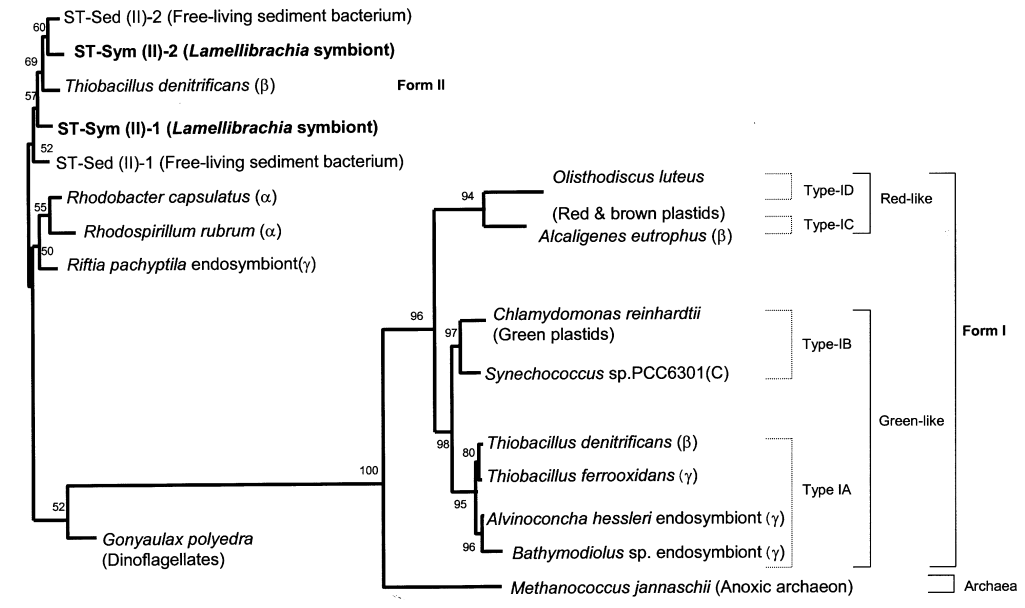

0.1
Fig. 3. Phylogenetic tree based on the deduced partial RuBisCO $c b b M$ amino acid sequences of ST-Sym(II)-1 and ST-Sym(II)-2 and those retrieved from the databases. The tree was constructed using the NJ method with the Kimura-2 correction parameter. Bootstrap values, calculated from 1000 replications, are expressed as percentages and only those values greater than $50 \%$ are shown at the nodes of the tree. The Greek letters in parentheses $(\alpha, \beta, \gamma)$ represent the classification of the species within the Proteobacteria made on the basis of $16 \mathrm{~S}$ rDNA data or on the results from other studies. $C$ in parentheses indicates a member of the Cyanobacteria. Bar, 0.1 substitutions per site.
$\mathrm{ST}-\operatorname{Sym}(16 \mathrm{~S})-1(\alpha)$

Lamellibrachia sp. symbiont $(\varepsilon)$ Lamellibrachia columna symbiont $(\gamma)$ Riftia pachyptila symbiont $(\gamma)$ Rhodobacter sulfidophilus $(\alpha)$ Rhodospirillum rubrum $(\alpha)$ Bathymodiolus endosymbiont $(\gamma)$ Escherichia coli $(\gamma)$
GGGATCTTAGACAATGGGCGCAGGC 346 GGAATATTGCACAATGGAGGAAACT 379 GGAATATTGGACAATGGGCGCAAGC 359 GGAATATTGGACAATGGGCGAAAGC 362 GGAATCTTGGACAATGGGGGAAACC 383 GGAATATTGCGCAATGGGGGCAACC 326 GGAATATTGGACAATGGGCGAAAGC 376 GGAATATTGCACAATGGGCGCAAGC 384
Fig. 4. Alignments of the $16 \mathrm{~S}$ rDNA sequences in the target region of the Lamellibrachia sp. symbiont-specific probe Lam384R [ST-Sym(16S)-1 sequence]. The shaded regions represent the mismatches with the corresponding nucleotides in the STSym(16S)-1 sequence. The accession numbers for the species shown in the alignment are: ST-Sym(16S)-1, AB042416; Lamellibrachia sp. endosymbiont, D83060; Lamellibrachia columna endosymbiont, U77481; Riftia pachyptila endosymbiont, U77478; Rhodobacter sulfidophilus, D13475; Rhodospirillum rubrum, D30778; Bathymodiolus endosymbiont, AB056868; E. coli, J01859. The letters in parentheses $(\alpha, \varepsilon, \gamma)$ represent the classification of the species within the Proteobacteria. The numbers of the aligned 16S rDNA positions are shown at the right side.

binding sites, such as those around the lysine at position 166 and the histidine at position 287, are conserved in the current ORUs (Schneider et al., 1990).

Species belonging to different phylogenetic groups, such as the $\alpha-, \beta$-, and $\gamma$-Proteobacteria, are usually displayed in individual clades in 16S-rDNA-based phylogenetic trees, where the species that belong to one phylogenetic group are always related to each other, in some way, within the clade (Fig. 1). In contrast to the 16S-rDNAbased phylogeny, the phylogram based on the RuBisCO genes localizes the species from the different 16S-rDNAbased phylogenetic groups into one clade. This can be seen in Fig. 3, where ST-Sym(II)-1 and ST-Sym(II)-2 ( $\alpha$ Proteobacteria) and Thiobacillus denitrificans (a member of the $\beta$-Proteobacteria) group together, and the cbbM sequence of the Riftia pachyptila endosymbiont (a member of the $\gamma$-Proteobacteria) clusters with members of the $\alpha$-Proteobacteria, Rhodobacter capsulatus and Rhodospirillum rubrum (Hernandez et al., 1996; Robinson et al., 1998). The inconsistency between the 16S-rDNA- and the RuBisCO-based phylograms is probably due to conservation of the RuBisCO genes among different phylogenetic groups of the Proteobacteria, Cyanobacteria and green eukarya (Delwiche \& Palmer, 1996). The conservation of the RuBisCO sequences has been suggested to be due to multiple horizontal gene transfers, involving the transfer of RuBisCO genes between the different phylogenetic lineages (Delwiche \& Palmer, 1996; Watson \& Tabita, 1997).

Three phylogenetic trees based on the partial $c b b M$ amino acid sequences of ST-Sym(II)-1, ST-Sym(II)-2 and sequences from the databases were constructed using the NJ, maximum-likelihood (ML) and maximumparsimony (MP) methods. These trees yielded similar, but not identical, topologies; hence, only the NJ-based tree is shown here (Fig. 3). Both NJ and MP analyses grouped the two endosymbiont ORUs into one cluster with $c b b M$ sequences from ST-Sed(II)-1 and ST-Sed(II)2 , recovered from sediment in the close vicinity of the studied tubeworm colony (Elsaied \& Naganuma, 2001). However, ML analysis did not group the current symbiont ORUs and those from ambient sediment bacteria into one cluster. Both ST-Sym(II)-1 and STSym(II)-2 shared 95 and $90 \%$ aa identity with the ORUs ST-Sed(II)-1 and ST-Sed(II)-2, respectively (Fig. 2).

The phylogenetic similarity between the tubeworm endosymbiont and ambient free-living bacteria based on the RuBisCO genes has also been demonstrated on the basis of $16 \mathrm{~S}$ rDNA analysis (Di Meo et al., 2000). This symbiont-ambient relationship implies that gutless tubeworms may acquire their endosymbionts through random ingestion of ambient bacteria during only a limited period when the tubeworm larva has a mouth opening (Di Meo et al., 2000). After acquisition of these ambient bacteria, adaptive species that bear a suitable $\mathrm{RuBisCO}$ form (I or II) may be selected as endosymbionts. Although the mechanism of acquisition and selection of the endosymbionts has not been examined so far, observations indicate that the tubeworms living in different habitats, i.e. seep-dwelling Lamellibrachia sp. and vent-dwelling Riftia pachyptila, prefer to har- 


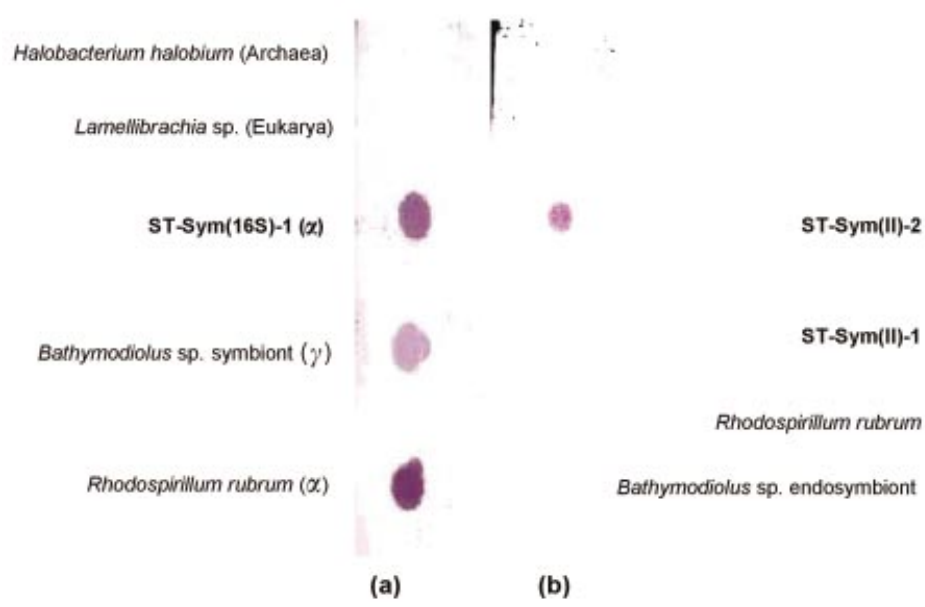

bour cbbM-bearing endosymbionts (Robinson et al., 1998). Establishment of the host-symbiont relationship is an intriguing process in terms of the evolution and biogeography of vestimentifera. More tubeworm species should be collected and analysed to explain the idea of the selection of $c b b M$-bearing endosymbionts. In terms of a genetic comparison between the $c b b M$ genes of tubeworm endosymbionts, ST-Sym(II)-1 and STSym(II)-2 shared 79 and $75 \%$ aa identity, respectively, with the cbbM amino acid sequence of the Riftia pachyptila endosymbiont from a hydrothermal vent in the East Pacific Rise (Robinson et al., 1998) (Fig. 2). This genetic variation among the RuBisCOs of vestimentiferan endosymbionts may be influenced by a variety of factors, including host genus, geographic variations in the location of the tubeworm and the sea-bed composition.

\section{Specificity and efficiency of the probes used for ISH}

The portion of the $16 \mathrm{~S}$ rDNA sequence used to construct oligonucleotide probe Lam-384R showed minimal nucleotide mismatching (four mismatches) with the $16 \mathrm{~S}$ rDNA sequence of the Lamellibrachia columna symbiont (Feldman et al., 1997), and had three mismatches with all of the aligned symbiont rDNA sequences (Fig. 4). Lam-384R was specific for the Lamellibrachia sp. endosymbiont, as shown by Southern dot-blot hybridization (Fig. 5b). The use of short oligonucleotide probes to localize $c b b M$ sequences within the trophosome by ISH was not successful in yielding a visible signal. This was due to the existence of a single copy of the RuBisCO gene in the genome: a single copy of $c b b M$ is not sufficient to give a signal when ISH is performed with a short oligonucleotide probe (Tabita, 1988). This is in
Fig. 5. Southern dot-blot hybridization analyses demonstrating the specificity of the 165 rDNA and cbbM probes. In (a) and (b), amplified rDNAs from a variety of species, including members of the archaea, the eukarya, bacterial symbionts (the current Lamellibrachia sp. endosymbiont, and the Bathymodiolus endosymbiont from which the RuBisCO form I probe was amplified) and a cultured member of the $\alpha$-Proteobacteria, Rhodospirillum rubrum, were used as templates. (a) Hybridization of the universal $16 \mathrm{~S}$ rDNA probe EUB338 to the rDNAs. (b) Hybridization of the Lamellibrachia sp. endosymbiont-specific 16S rDNA probe Lam-384R to the rDNAs. (c) Hybridization of the RuBisCO cbbM probe ST-Sym(II)-2 to the amplified $c b b M$ products from the current Lamellibrachia sp. endosymbiont and from Rhodospirillum rubrum, and to the RuBisCO form I $c b b L$ amplified from the Bathymodiolus endosymbiont. DNA (50 ng) was blotted for each dot on the membrane. The probes were labelled with digoxigenin and the dot colours were developed by the reaction of an alkaline phosphatase on the 5-bromo-4-chloro-3-indolyl-phosphate $p$-toluidine salt. good contrast with the $16 \mathrm{~S}$ rRNA, which has a high copy number within bacterial cells and can be detected using short, specific oligonucleotide probes such as Lam-384R (Cary et al., 1993). The polynucleotide $c b b M$ probe STSym(II)-2 (400 bp) was efficient in yielding a sufficient cbbM ISH signal, but the use of this probe resulted in the loss of the ability to distinguish between the subtle differences in the sequences of ST-Sym(II)-1 and STSym(II)-2, as indicated by dot-blot hybridization on the nylon membrane (Fig. 5c). This was the result of a tradeoff between signal intensity and specificity. Hence, the ST-Sym(II)-2 probe was used to visualize all of the possible RuBisCO form II sequences within the trophosome, including the ST-Sym(II)-1 sequence. However, ISH with the symbiont-specific $16 \mathrm{~S}$ rDNA probe Lam-384R was used as a control for the localization of the signal produced by the $c b b M$ probe, ST-Sym(II)-2. The ISH signals of the symbiont-specific $16 \mathrm{~S}$ rDNA probe Lam-384R and the $c b b M$ probe ST-Sym(II)-2 overlapped almost completely in two consecutive trophosome sections (Fig. 6b, c). This reflects the exact localization of the endosymbiont $c b b M$ sequences within the trophosome.

\section{ISH using the 16S rDNA and RuBisCO probes}

Our initial approach to studying chemoautrotrophic endosymbiosis within the trophosome was to co-localize the symbiotic $16 \mathrm{~S}$ rRNA and $c b b M$ sequences within this tissue. However, the application of the fluorescence in situ hybridization (FISH) technique to the trophosomal tissue of the Lamellibrachia sp. was unsuccessful. This was due to high background fluorescence, which resulted from the accumulation of sulfur particles in the trophosome that made the tissue prone to auto-fluor- 

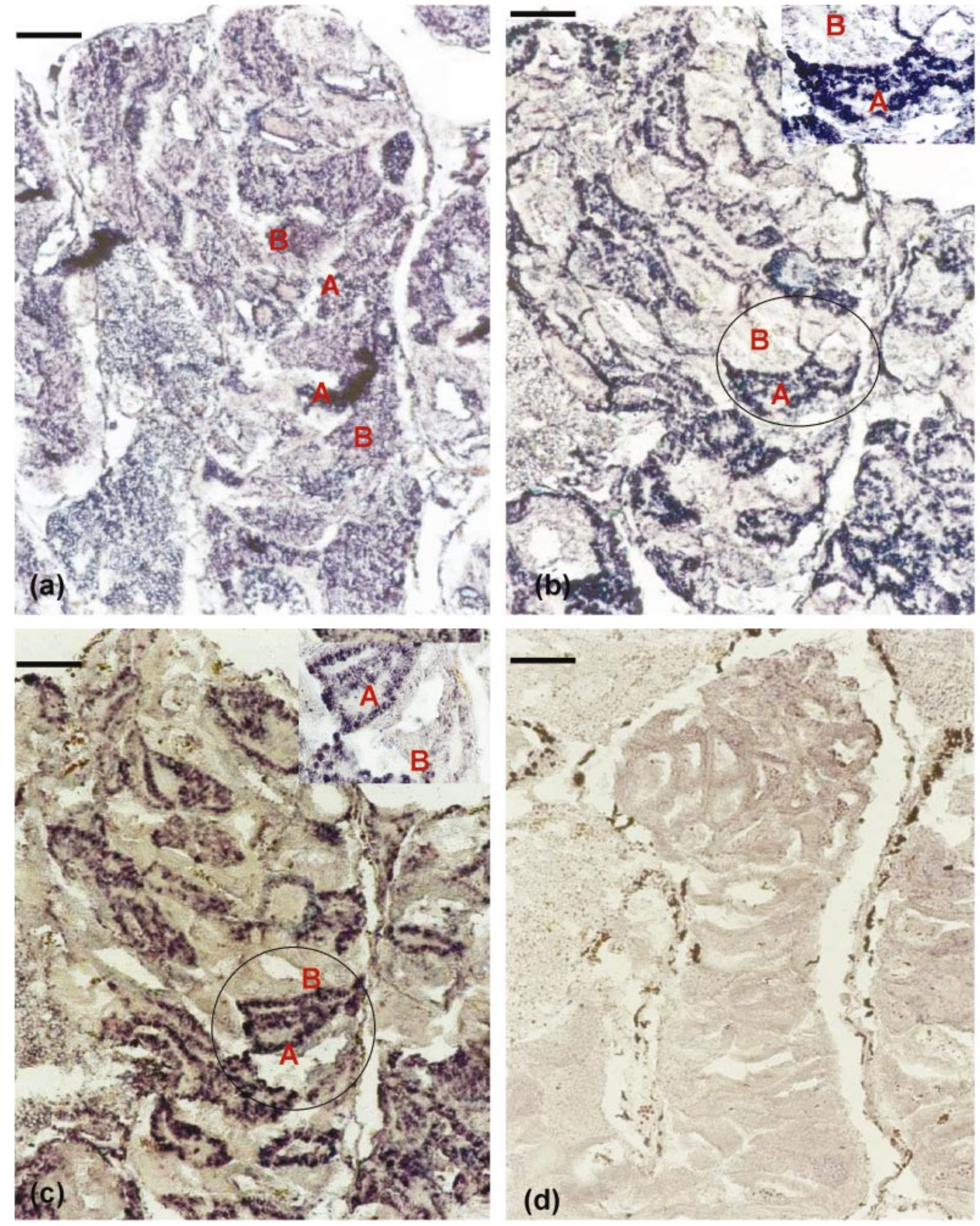

Fig. 6. For legend see facing page.

escence (Fisher, 1990; Naganuma et al., 1997a). This is in contrast with the use of FISH to detect symbiotic bacteria in the hydrothermal vent mussel gill that has direct contact with ambient water. The mussel gill may 

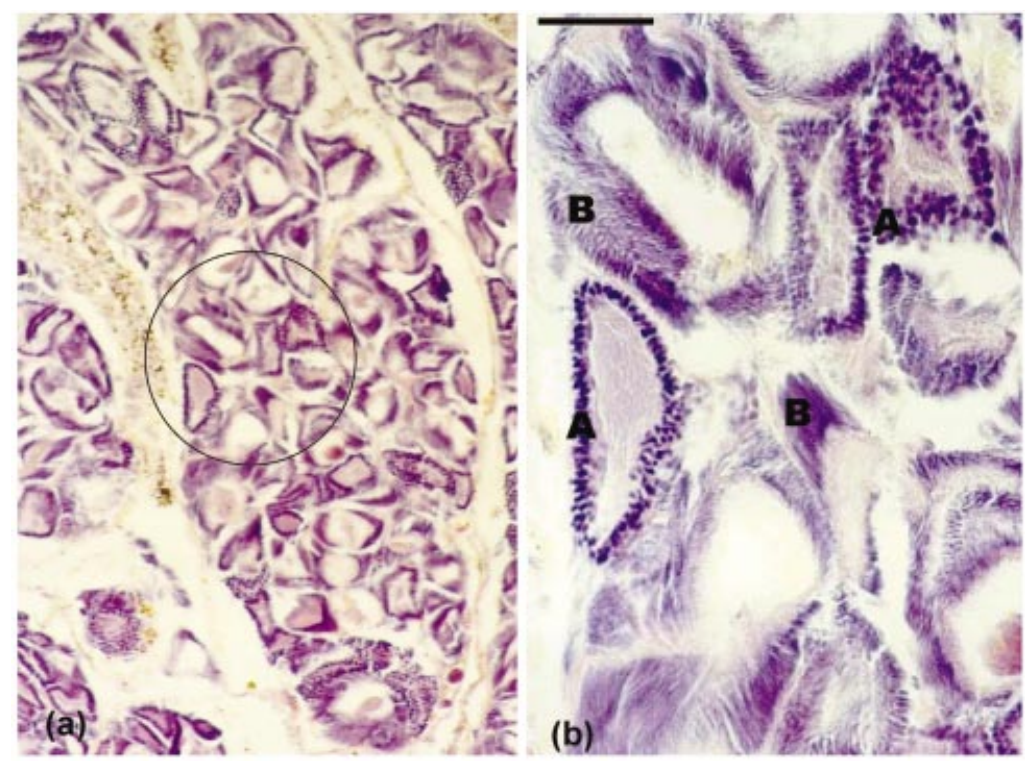

Fig. 7. (a) Cross-section of trophosomal tissue stained with haematoxylin/eosin. The staining shows the histological structures of the symbiont-containing region. (b) Magnified part of the trophosome section showing the trophosome lobules whose peripheries contain two types of cells, i.e. the coccoid (A) and the filamentous (B) cells. Bar, $50 \mu \mathrm{m}$.

serve as the drainage site for deposited sulfur and, consequently, yields less background fluorescence than the vestimentiferan internal organ, the trophosome (Fisher, 1990; Distel \& Cavanaugh, 1994; Distel et al., 1995). However, the detection signal has been shown to be enhanced by using a digoxigenin-labelled probe via the formation of an insoluble coloured precipitate. This probing method is not subject to background interference caused by the tissue, and was found to be suitable in the detection of dual symbiosis in the deepsea cold-seep thyasirid clam Maorithyas hadalis (Fujiwara et al., 2001). Thus, ISH using digoxigeninlabelled probes is most helpful when a strong background fluorescence, or cellular auto-fluorescence, prevents or disturbs the detection of probe-conferred fluorescence, e.g. the detection of endosymbiotic bacteria in the trophosome of Lamellibrachia sp. (current study) and the detection of symbiotic Cyanobacteria in plant sections (Zarda et al., 1991; Amann et al., 1995; Naganuma et al., 1997a).

The vestimentiferan trophosome consists of lobules. The symbiont-bearing cells, the bacteriocytes, are concentrated at the peripheries of the lobules (Hand, 1987). Two types of cells, coccoid and filamentous, were apparently observed at the peripheries of the lobules stained with haematoxylin/eosin (Fig. 7a, b). Both of the cell types were in situ hybridized with the universal eubacterial 16S-rRNA-targeted probe EUB338 (Fig. 6a). The occurrence of more than one bacterial morphotype in the vestimentifera trophosome has been reported in a relatively small number of studies (Cavanaugh et al., 1981; Cavanaugh, 1985; Fisher, 1990; Naganuma et al., 1997a, b; Bright et al., 2000). The occurrence of multiple bacterial morphotypes within the trophosome may reflect the complexity of the geochemical processes seen in tubeworm habitats. Some seep habitats, such as the area of sample collection for this study, have abundant methane in the water and sediment, but hydrogen sulfide is only present in the sediment (Sakai et al., 1987). The seep-dwelling tubeworms are known to incorporate hydrogen sulfide from the sediment via their posterior end, which is buried in the sediment (Julian et al., 1999). Hence, the existence of a diverse microflora in the trophosome of the tubeworm Lamellibrachia sp. has been hypothesized to be correlated with the need to utilize sulfur compounds available from the surrounding environment, using methane as a reducing agent (Naganuma et al., 1997a; Naganuma, 1998).

The polynucleotide $c b b M$ probe ST-Sym(II)-2, which hybridized with all possible $c b b M$ sequences within the trophosome, and the $16 \mathrm{~S}$ rDNA probe Lam-384R produced signals in the same coccoid cells (Fig. 6b, c). This implies that the coccoid cells may carry ST-Sym(II)1 and ST-Sym(II)-2, the two $c b b M$ ORUs recorded by amino acid analysis. It is not clear whether these two $c b b M$ sequences occur in only one endosymbiotic species or in two endosymbiotic species. However, the $16 \mathrm{~S}$ rDNA analysis showed only one sequence for one endosymbiotic species, which was localized in the coccoid cells. Moreover, this result indicates that the coccoid cells at the peripheries of the lobules are the sites of $\mathrm{CO}_{2}$ fixation within the trophosome. These coccoid cells have been observed to accumulate sulfur, as shown by X-ray microanalysis of the trophosome content

Fig. 6. Micrographs of four consecutive cross sections of the trophosomal tissue showing ISH with the digoxigeninlabelled probes. (a) Hybridization with the universal eubacterial probe EUB338. Higher colour intensity in some coccoid cells (A) compared to that in the filamentous cells (B) indicates a gradient of available 16S rRNA and, possibly, a gradient in metabolic activity. (b) Hybridization with the endosymbiont-specific 16S rDNA probe Lam-384R. (c) Hybridization with the RuBisCO form II $c b b M$ probe ST-Sym(II)-2. (d) Hybridization with the RuBisCO form I cbbL probe Bathy(cbbL)-1 as a negative control. Bar, $50 \mu \mathrm{m}$. 
(Naganuma et al., 1997a). This sulfur accumulation seems to be related to autotrophy, in which sulfide is oxidized to elemental sulfur.

The filamentous cells showed a hybridization signal with the universal $16 \mathrm{~S}$ rDNA probe EUB338, but not with the 16S-rDNA-specific probe Lam-384R nor with the RuBisCO form II probe ST-Sym(II)-2 (Fig. 6a-c). This may indicate that these filamentous bacterial cells have a different function, and that they are not involved in carbon fixation. Alternatively, these filamentous cells may have been extracellular bacteria which could not be detected by $16 \mathrm{~S}$ rDNA sequence analysis, as only the autotrophic endosymbiotic bacteria contained within the trophosome were targeted, and the trophosomal tissue used for DNA extraction was pre-treated to remove any extracellular bacteria. The same filamentous cells have been observed previously in the trophosome of the same Lamellibrachia sp. used in this study and are related to the $\varepsilon$-Proteobacteria (Naganuma et al., 1997a). Certain species belonging to the $\varepsilon$-Proteobacteria are known to inhabit animal cavities as extracellular microaerophilic bacteria and are capable of sulfur oxidation (Simbert, 1984; Penner, 1988; Naganuma et al., 1997a, b). This seems to be an adaptive trait for the environmental conditions within the trophosome. The use of the term 'symbiotic' to describe these filamentous cells should be avoided until their commensal functions have been demonstrated.

No ISH signal was observed with the RuBisCO form I $c b b L$ probe, Bathy $(c b b L)-1$, when it was applied to the trophosome section (Fig. 6d). This result was in agreement with the inability to amplify the RuBisCO form I gene $(c b b L)$ from the bulk trophosomal DNA.

The use of ISH for the localization of the RuBisCO form II sequences will facilitate our understanding of the autotrophic microbial processes within the trophosome. Further investigations should be done to show the metabolic relationships between autotrophic and nonautotrophic microflora within the trophosome of this gutless, methane-seep tubeworm, namely Lamellibrachia sp.

\section{ACKNOWLEDGEMENTS}

We thank all of the teams of the DSV Shinkai 2000 for their help in the collection of samples. Our grateful thanks also go to Drs Y. Yoshimura and Zheng Weiming, Hiroshima University, for their help in the preparation of histological sections for ISH. This work was partly supported by the Special Co-ordination Fund 'Archaean Park Project' from the Ministry of Education, Culture, Sports, Science and Technology (MEXT) of Japan, and by the Collaborative Research Fund 'Strategy for Life under Extreme Conditions' of the Graduate University for Advanced Studies, Japan.

\section{REFERENCES}

Altschul, S. F., Gish, W., Miller, W., Myers, E. W. \& Lipman, D. J. (1990). Basic local alignment search tool. J Mol Biol 215, 403-410.

Amann, R. I., Binder, B. J., Olson, R. J., Chisholm, S. W., Devereux, R. \& Stahl, D. A. (1990). Combination of $16 \mathrm{~S}$ rRNA-targeted oligonucleotide probes with flow cytometry for analyzing mixed microbial populations. Appl Environ Microbiol 56, 1919-1925.

Amann, R. I., Ludwig, W. \& Schleifer, K.-H. (1995). Phylogenetic identification and in situ detection of individual microbial cells without cultivation. Microbiol Rev 59, 143-169.

Bright, M., Keckeis, H. \& Fisher, C. R. (2000). An autoradiographic examination of carbon fixation, transfer and utilization in the Riftia pachyptila symbiosis. Mar Biol 136, 621-632.

Cary, S. C., Warren, W., Anderson, E. \& Giovannoni, S. J. (1993). Identification and localization of bacterial endosymbionts in hydrothermal vent taxa with symbiont-specific polymerase chain reaction amplification and in situ hybridization techniques. Mol Mar Biol Biotechnol 2, 51-62.

Cavanaugh, C. M. (1983). Symbiotic chemoautotrophic bacteria in marine invertebrates from sulfide-rich habitats. Nature 302, 58.

Cavanaugh, C. M. (1985). Symbiosis of chemoautotrophic bacteria and marine invertebrates from hydrothermal vents and reducing sediment. Biol Soc Wash Bull 6, 373-388.

Cavanaugh, C. M., Gardiner, S. L., Jones, M. L., Jannasch, H. W. \& Waterbury, J. B. (1981). Prokaryotic cells in the hydrothermal vent tube worm, Riftia pachyptila: possible chemoautotrophic symbionts. Science 213, 340-342.

Dealtry, G. \& Rickwood, D. (editors). (1992). Cell Biology Labfax, p. 254. Oxford: BIOS Scientific.

De Burgh, M. E., Juniper, S. K. \& Singla, C. L. (1989). Bacterial symbiosis in Northeast Pacific Vestimentifera : a TEM study. Mar Biol 101, 97-105.

DeLong, E. F. (1992). Archaea in coastal marine environments. Proc Natl Acad Sci U S A 89, 5685-5689.

Delwiche, C. F. \& Palmer, J. D. (1996). Rampant horizontal transfer and duplication of RuBisCO genes in eubacteria and plastids. Mol Biol Evol 13, 873-882.

Di Meo, C. A., Wilbur, A. E., Holben, W. E., Feldman, R. A., Vrijenhoek, R. C. \& Cary, S. C. (2000). Genetic variation among endosymbionts of widely distributed vestimentiferan tubeworms. Appl Environ Microbiol 66, 651-658.

Distel, D. L. \& Cavanaugh, C. M. (1994). Independent phylogenetic origins of methanotrophic and chemoautotrophic bacterial endosymbioses in marine bivalves. J Bacteriol 176, 1932-1938.

Distel, D. L., Felbeck, H. \& Cavanaugh, C. M. (1994). Evidence for phylogenetic congruence among sulfur-oxidizing chemoautotrophic bacterial endosymbionts and their bivalvia hosts. J Mol Evol 38, 533-542.

Distel, D. L., Lee, H. K. \& Cavanaugh, C. M. (1995). Intracellular coexistence of methano- and thioautotrophic bacteria in a hydrothermal vent mussel. Proc Natl Acad Sci U S A 92, 9598-9602.

Elsaied, H. \& Naganuma, T. (2001). Phylogenetic diversity of ribulose-1,5-bisphosphate carboxylase/oxygenase large-subunit genes from deep-sea microorganisms. Appl Environ Microbiol 67, 1751-1765.

Felbeck, H. (1981). Chemoautotrophic potential of the hydrothermal vent tubeworm Riftia pachyptila Jones (vestimentiferan). Science 213, 336-338.

Felbeck, H. \& Childress, J. J. (1988). Riftia pachyptila: a highly integrated symbiosis. Oceanol Acta 8, 131-138.

Felbeck, H., Childress, J. H. \& Somero, G. N. (1981). CalvinBenson cycle and sulfide oxidation enzymes in animals from sulfide-rich habitats. Nature 293, 291-293.

Feldman, R. A., Black, M. B., Cary, C. S., Lutz, R. A. \& Vrijenhoek, R. C. (1997). Molecular phylogenetics of bacterial endosymbionts 
and their vestimentiferan hosts. Mol Mar Biol Biotechnol 6, 268-277.

Felsenstein, J. (1989). PHYLIP - Phylogeny inference package (version 3.2). Cladistics 5, 164-166.

Fisher, C. R. (1990). Chemoautotrophic and methanotrophic symbiosis in marine invertebrates. Rev Aquat Sci 2, 399-436.

Fujiwara, Y., Kato, C., Masui, N., Fujikura, K. \& Kojima, S. (2001). Dual symbiosis in the cold-seep thyasirid clam Maorithyas hadalis from the hadal zone in the Japan Trench, western Pacific. Mar Ecolog Prog Ser 214, 151-159.

Godon, J. J., Zumstein, E., Dabert, P., Habouzit, F. \& Molletta, R. (1997). Molecular microbial diversity of an anaerobic digestor as determined by small-subunit rDNA sequence analysis. Appl Environ Microbiol 63, 2802-2813.

Hand, S. C. (1987). Trophosome ultrastructure and the characterization of isolated bacteriocytes from invertebrate-sulfur bacteria symbiosis. Biol Bull 173, 260-276.

Haygood, M. G. (1996). The potential role of functional differences between RuBisCO forms in governing expression in chemoautotrophic symbiosis. Limnol Oceanogr 41, 370-371.

Hernandez, J. M., Baker, S. H., Lorbach, S. C., Shively, J. M. \& Tabita, F. R. (1996). Deduced amino acid sequence, functional expression, and unique enzymatic properties of the form I and form II ribulose bisphosphate carboxylase/oxygenase from the chemoautotrophic bacterium Thiobacillus denitrificans. J Bacteriol 178, 347-356.

Imhoff, J. (1989). Genus Rhodobacter. In Bergey's Manual of Systematic Bacteriology, vol. 3, pp. 1668-1672. Edited by J. T. Staley, M. P. Bryant, N. Pfennig \& J. G. Holt. Baltimore: Williams \& Wilkins.

Julian, D., Gail, F., Wood, E., Arp, A. \& Fisher, C. (1999). Roots as a site of hydrogen sulfide uptake in the hydrocarbon seep vestimentiferan Lamellibrachia sp. J Exper Biol 202, 2245-2257.

Kellogg, E. A. \& Juliano, N. D. (1997). The structure and function of $\mathrm{RuBisCO}$ and their implications for systematic studies. Am J Bot 84, 413-428.

Miziorko, H. M. \& Lorimer, G. H. (1983). Ribulose-1,5-bisphosphate carboxylase-oxygenase. Annu Rev Biochem 52, 507-535.

Naganuma, T. (1998). A hypothetical microbial consortium that stabilizes oxygen-gradient in chemosynthetic microenvironment. Supramolec Sci 5, 439-443.

Naganuma, T., Naka, J., Okayama, Y., Minami, A. \& Horikoshi, K. (1997a). Morphological diversity of the microbial population in a vestimentiferan tubeworm. J Mar Biotechnol 5, 199-123.

Naganuma, T., Kato, C., Hirayama, H., Moriyama, N., Hashimoto, J. \& Horikoshi, K. (1997b). Intracellular occurrence of $\varepsilon$-Proteobacteria $16 \mathrm{~S}$ rDNA sequences in the vestimentiferan trophosome. J Oceanogr 53, 193-197.

Nargang, F., Mclntosh, L. \& Somerville, C. (1984). Nucleotide sequence of the ribulose bisphosphate carboxylase gene from Rhodospirillum rubrum. Mol Gen Genet 193, 220-224.

Newman, J. \& Gutteridge, S. (1993). The X-ray structure of Synechococcus ribulose-bisphosphate carboxylase/oxygenaseactivated quaternary complex at $2 \cdot 2-\AA$ resolution. J Biol Chem 268, 25876-25886.

Olsen, G. J., Larsen, N. \& Woese, C. R. (1991). The ribosomal RNA database project. Nucleic Acids Res 19 Suppl., 2017-2021.

Page, R. D. M. (1996). TREEVIEW: An application to display phylogenetic trees on personal computers. Comput Appl Biosci 12, 357-358.
Penner, J. L. (1988). The genus Campylobacter: a decade of progress. Clin Microbiol Rev 1, 157-172.

Robinson, J. \& Cavanaugh, C. M. (1995). Expression of form I and form II RuBisCO in chemoautotrophic symbiosis: implications for the interpretation of stable carbon isotope values. Limnol Oceanogr 40, 1496-1502.

Robinson, J. J., Stein, J. L. \& Cavanaugh, C. M. (1998). Cloning and sequencing of a form II ribulose-1,5-bisphosphate carboxylase/oxygenase from the bacterial symbiont of the hydrothermal vent tubeworm Riftia pachyptila. J Bacteriol 180, 1596-1599.

Saitou, N. \& Nei, M. (1987). The neighbor-joining method: a new method for reconstructing phylogenetic trees. Mol Biol Evol 4, 406-425.

Sakai, H., Gamo, T., Endow, K. \& 7 other authors (1987). Geochemical study of the bathyal seep communities at the Hatsushima site, Sagami bay, Central Japan. Geochem J 21, 227-236.

Schneider, G., Lindqvist, Y. \& Lundqvist, T. (1990). Crystallographic refinement and structure of ribulose-1,5-bisphosphate carboxylase from Rhodospirillum rubrum at $1.7 \AA$ resolution. J Mol Biol 211, 989-1008.

Simbert, R. M. (1984). Genus Campylobacter. In Bergey's Manual of Systematic Bacteriology, vol. 1, pp. 111-118. Edited by N. R. Krieg \& J. G. Holt. Baltimore: Williams \& Wilkins.

Stahl, D., Lane, D., Olsen, G. \& Pace, N. (1984). Analysis of hydrothermal vent-associated symbionts by ribosomal RNA sequences. Science 224, 409-411.

Stein, J. L. \& Felbeck, H. (1993). Kinetic and physical properties of a recombinant $\mathrm{RuBisCO}$ from a chemoautotrophic endosymbiont. Mol Mar Biol Biotechnol 2, 280-290.

Stein, J. L., Haygood, M. \& Felbeck, H. (1990). Nucleotide sequence and expression of a deep-sea ribulose-1,5-bisphosphate carboxylase gene cloned from a chemoautotrophic bacterial endosymbiont. Proc Natl Acad Sci U S A 87, 8850-8854.

Tabita, F. R. (1988). Molecular and cellular regulation of autotrophic carbon dioxide fixation in microorganisms. Microbiol Rev 52, 155-189.

Tabita, F. R. (1995). The biochemistry and metabolic regulation of carbon metabolism and $\mathrm{CO}_{2}$ fixation in purple bacteria. In Anoxygenic Photosynthetic Bacteria, pp. 885-914. Edited by R. E. Blankenship, M. T. Madigan \& C. E. Bauer. Dordrecht: Kluwer.

Thompson, J. D., Higgins, D. G. \& Gibson, T. J. (1989). CLUSTAL w : Improving the sensitivity of progressive multiple sequence alignments through sequence weighting, position-specific gap penalties and weight matrix choice. Nucleic Acids Res 22, 4673-4680.

Watson, G. M. \& Tabita, F. R. (1997). Microbial ribulose 1,5bisphosphate carboxylase/oxygenase: a molecule for phylogenetic and enzymological investigation. FEMS Microbiol Lett 146, 13-22.

Watson, G. M., Yu, J. P. \& Tabita, F. R. (1999). Unusual ribulose 1,5-bisphosphate carboxylase/oxygenase of anoxic Archaea. J Bacteriol 181, 1569-1575.

Zarda, B., Amann, R., Wallner, G. \& Schleifer, K.-H. (1991). Identification of single bacterial cells using digoxigenin-labelled, rRNA-targeted oligonucleotides. J Gen Microbiol 137, 28232830.

Received 23 February 2001; revised 3 January 2002; accepted 1 February 2002. 